Archived version from NCDOCKS Institutional Repository http://libres.uncg.edu/ir/asu/

\title{
Appalachỉan
}

B O O N E, N O R T H C A R O L I N A

\section{Creating Digital Scholarship Services At Appalachian State University}

\author{
By: Pam Mitchem and Dea Miller Rice
}

\begin{abstract}
This article reviews literature related to building digital scholarship centers and explores the experience of Appalachian State University Libraries in planning and implementing a digital scholarship program. Appalachian surveyed its faculty, performed a gap analysis of existing services, compared programs at other universities, and inventoried services provided by campus partners to determine service offerings. The following case study will discuss the planning process and the first year of implementation, exploring some of the challenges, such as a lack of understanding and hostility toward new modes of scholarship. Some of the lessons learned include the need for adequate research and planning time as well as education for, and communication with, key stakeholders.
\end{abstract}

Mitchem, Pamela Price \& Rice, Dea Miller. "Creating Digital Scholarship Services at Appalachian State University." portal: Libraries and the Academy, vol. 17 no. 4, 2017, pp. 827-841. Project MUSE, doi:10.1353/pla.2017.0048. Publisher version of record available at: https://muse.jhu.edu/article/672186 


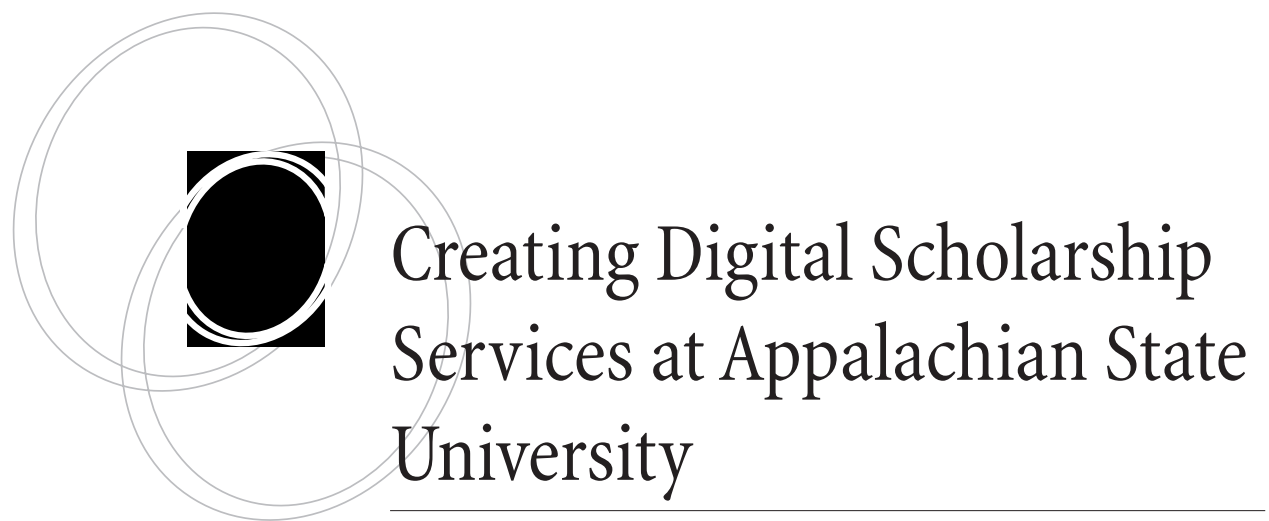

Pamela Price Mitchem and Dea Miller Rice

abstract: This article reviews literature related to building digital scholarship centers and explores the experience of Appalachian State University Libraries in planning and implementing a digital scholarship program. Appalachian surveyed its faculty, performed a gap analysis of existing services, compared programs at other universities, and inventoried services provided by campus partners to determine service offerings. The following case study will discuss the planning process and the first year of implementation, exploring some of the challenges, such as a lack of understanding and hostility toward new modes of scholarship. Some of the lessons learned include the need for adequate research and planning time as well as education for, and communication with, key stakeholders.

\section{Introduction}

A ppalachian State University is a regional comprehensive university in Boone, North Carolina, serving more than 17,000 students and employing close to 900 faculty, including non-tenure track. The University Libraries strives, its mission statement says, "To cultivate an environment where people discover, create, and share information that reflects the acquisition of 21st-century knowledge and skills. We are active partners in advancing the University's principles of sustainability, social justice, inclusion, and global citizenship." 1 To further these principles, the newly created Digital Scholarship and Initiatives team at the University Libraries engages and partners with Appalachian faculty members, students, library colleagues, and the community to support new scholarship in a constantly changing digital landscape.

Appalachian State's University Libraries formed a Digital Initiatives Task Force in November 2014 that spent five months extensively researching Appalachian's digital services, faculty scholarship needs, and programs at other universities. This task force 
was initiated to determine how we could expand our program to help support and collaborate with faculty on digital scholarly projects. Requests from faculty for help with digital collections and exhibits were steadily increasing, and we were not prepared to manage these requests with our current structure. The report, completed in April 2015, recommended that a team be formed to coordinate existing services and develop new ones to support faculty and student digital scholarship. The new library team, Digital Scholarship and Initiatives (DSI), began serving the university on July 1, 2015.

Diane Goldenberg-Hart writes in the introduction to the 2016 "Report of a CNI [Coalition for Networked Information]-ARL [Association of Research Libraries] Workshop: Planning a Digital Scholarship Center":

The diverse needs of any campus population, combined with constantly evolving modes of scholarship, can make it very difficult for colleges and universities to establish strategies that deliver effective services with broad impact. Furthermore, sustaining flexible and innovative programming can be especially challenging. ${ }^{2}$

Academic libraries have grappled for some time with how to provide digital research services to their faculty and student constituents. This paper is a case study of our experience in planning and launching a digital scholarship program in our library. It also explores other institutions' experiences, outlines challenges faced and lessons learned, and provides a checklist to help others plan for digital scholarship programs.

\section{Digital This, Digital That: How Do We Define "the Center"?}

In this article, we consider the term "digital scholarship" in its broadest sense, leaving it to individual institutions to refine the definition for themselves after considering their

Academic libraries have grappled for some time with how to provide digital research services to their faculty and student constituents. This paper is a case study of our experience in planning and launching a digital scholarship program in our library. own needs. Broadly defined, digital scholarship is the use of digital tools to create, analyze, and disseminate scholarly products. Support for digital scholarship comes in many forms. It can be library-centered, or it may develop in information technology (IT) or academic departments. Some of the earliest centers devoted to digital scholarship were digital humanities centers (DHCs), many of which were established in academic departments.

Digital scholarship centers (DSCs) can be found in IT departments or libraries, or they may be independent. Though DHCs focus specifically on the humanities and DSCs encompass all disciplines, there are many similarities between the two. The following is a review of studies that examine digital humanities centers and digital scholarship centers.

\section{Digital Humanities Centers}

One of the first digital humanities projects was the Text Encoding Initiative, initiated in 1984 by a group of scholars in the humanities, linguistics, and computer science to de- 
velop an encoding scheme for humanities electronic texts. Since then, digital humanities centers and programs have proliferated in colleges and universities across the country. There are many definitions and interpretations of digital humanities and what a digital humanities center or program should encompass. Jennifer Schaffner and Ricky Erway define digital humanities as the "application of digital resources and methods to humanistic inquiry." ${ }^{3}$ Chris Sula similarly describes the digital humanities as focusing on the "application of computing technology to humanistic inquiries and on humanistic reflections on the significance of that technology."

Diane Zorich, in her 2008 report A Survey of Digital Humanities Centers in the United States, concludes that digital humanities centers vary in their characteristics and services. Her expansive definition of DHCs is based on two assumptions: (1) digital humanities in the broadest sense amounts to "humanities-based research, teaching and intellectual engagement conducted with digital technologies and resources"; and (2) the center can be either physical, virtual, or a hybrid of the two. ${ }^{5}$ A hybrid model may encompass a few core staff who work with partners from other departments to provide a suite of services. The centers in Zorich's study were housed in various departments other than the library or were independent.

\section{Digital Scholarship Centers}

Digital scholarship is a broader concept, encompassing all disciplines, not just the humanities. Edward Ayers, in "Does Digital Scholarship Have a Future?" (2013), defines the enterprise as "discipline-based scholarship produced with digital tools and presented in digital form." ${ }^{6}$ Charles Inskip, in "From Information Literacy to Digital Scholarship: Challenges and Opportunities," discusses a broad range of research that places digital scholarship and information Digital scholarship centers differ from digital humanities centers in that they have a different administrative reporting structure, more diverse disciplines, and a wider range of clientele. literacy within a broader framework of digital literacy. He defines digital scholarship as "the ability to participate in emerging academic, professional and research practices that depend on digital systems." 7 This definition is not far removed from the one articulated by Ayers.

In the Coalition for Networked Information (CNI) 2014 report "Digital Scholarship Centers: Trends \& Good Practice," Joan Lippincott and Diane Goldenberg-Hart noted that digital scholarship centers differ from digital humanities centers in that they have a different administrative reporting structure, more diverse disciplines, and a wider range of clientele. They also provide tools, hardware, software, storage, expertise, and multiple levels of program support for all members of the campus community. ${ }^{8}$ Nearly all the centers in the CNI report were in academic libraries.

\section{Models: What Does a Digital Scholarship Center Do?}

A review of the literature finds multiple models for digital scholarship services. The CNIARL (Coalition for Networked Information-Association of Research Libraries) report 
"Planning a Digital Scholarship Center" (2016) underscores that no one model will fit every institution and that centers are individualized according to the specific needs of their parent organization. Understanding the organizational culture and building partnerships with its constituents are necessary for the sustainability of the center. Lippincott and Goldenberg-Hart's 2014 CNI report stated that the most common services among the participating centers in their workshop were: consultation on digital technologies; digital preservation and curation; and digital project management workshops related to these topics.

Zorich, an information management consultant for the Council on Library Information Resources (CLIR), notes that centers may build digital collections, offer tools, provide training and programs such as lectures and conferences, give consultation, facilitate collaboration, make spaces available for experimentation, and offer repository and preservation support. Zorich groups DHCs into two categories: center-focused and resource-focused programs. The former require a physical location with multiple services and programs for diverse audiences. The latter are "organized around a primary resource, located in a virtual space" and serve a "specific group of individuals." ${ }^{\prime 9}$ For example, the center might be a digital library or archive focused on a subject specialty.

The CLIR report details the variances in physical and virtual locations, governance, staffing, reporting structures, sustainability, services, partnerships, and tools, providing a good overview of how other centers are modeled. Zorich suggests that partnering

Libraries can respond to digital humanists' needs in many ways, from a virtual $\mathrm{DH}$ center, where the library packages existing services, to creating a physical center with space, equipment, funding, and dedicated staff. with other campus units to provide resources may be more effective than putting everything in one center.

Schaffner and Erway state that libraries can respond to digital humanists' needs in many ways, from a virtual $\mathrm{DH}$ center, where the library packages existing services, to creating a physical center with space, equipment, funding, and dedicated staff. ${ }^{10}$ The virtual center is a popular option because it requires fewer changes in organizational structure and funding. As evidence of this, the ARL 2011 SPEC [Systems and Procedures Exchange Center] Kit on digital humanities reports that about 8 percent of responding libraries have centers, with about half the responding libraries providing ad hoc services. ${ }^{11}$

Joyce Ogburn, in "A Report on the Digital Humanities and Concept Paper for a Virtual Center for Interdisciplinary Knowledge Arts" (2013), categorized digital humanities centers as: (1) tool based, focusing on general services and tools or creating new tools; (2) theme based, with projects and tools developing around a community of interest or like projects; (3) networked, utilizing partnerships across the organization, dynamic approaches, and many different tools and communities; and (4) individualist, relying on individual or small group one-off projects. ${ }^{12}$

Chris Sula ("Digital Humanities and Libraries: A Conceptual Model") and Joris van Zundert ("If You Build It, Will We Come? Large Scale Digital Infrastructures as a Dead End for Digital Humanities") argue for smaller-scale rather than enterprise-wide 
solutions. Sula suggests that libraries should provide services based on user needs rather than offer a general solution. ${ }^{13}$ Van Zundert asserts, "Methodological innovation and advancing the modeling of humanities data and heuristics [are] better served by flexible small-scale research focused development practices." Big, institutionally based digital infrastructures, he argues, "deliver empty infrastructures bereft of useful tools and data." He notes the difference between simply using digital technologies and being innovative with them, observing that standardization is the enemy of innovation and that the infrastructure should be simple: "Digital humanities needs open and inclusive platforms with a web service based approach."14

In contrast, Jennifer Vinopal and Monica McCormick describe the transition from the small-scale approach to an enterprise level in their article "Supporting Digital Scholarship in Research Libraries: Scalability and Sustainability." Vinopal and McCormick found that support for faculty requests is varied and can be simple and brief or complex and lengthy, depending on the project. New York University (NYU) Libraries approached the issue by utilizing "small discipline-focused computing groups" to support projects in the different disciplines. However, they could support only a few faculty per year and needed a broader approach, which took the form of an enterprise-level academic tool and greater support services for more faculty. But that approach does little to support "innovative web-based collaboration communication, and publication activities." ${ }^{15}$ Scholars need dissemination tools, interoperable tools, repositories, and faculty collaboration.

Ultimately, NYU Libraries developed a four-tiered model of sustainable and scalable services through standardization employing reusable tools and platforms: (1) enterprise academic and administrative tools that include wikis, e-mail, and file storage; (2) standard research services, such as institutional repositories, data analysis tools, and Web exhibits; (3) enhanced research services, which are custom designed for the project; and (4) applied research and development (R\&D)-grant funded services. ${ }^{16}$

\section{Figuring It All Out}

There is no way to avoid the research needed to determine what digital scholarship support services your library should offer. Fortunately, there are some models for accomplishing this task. Vinopal and McCormick note that in determining services libraries must: (1) utilize a well-defined selection process to manage demand; (2) determine scalability and sustainability goals; (3) identify the audience; (4) provide tools, services, and projects that meet the library's goals; (5) create a service-level agreement that specifies hours, availability, functionality, service and customer support levels, customer and service provider obligations, and fees; and (6) institute a portfolio-management process. ${ }^{17}$

To learn how to meet faculty needs, NYU Libraries worked with their subject specialists and faculty to perform a service gap analysis. NYU interviewed peer institutions and developed three general types of service models: (1) digital collections, which 
provide infrastructure for digitization, preservation, and access; (2) digital research and publishing services, which support a wide range of needs with little customization; and (3) digital scholarship or digital humanities centers, which are "scholar-driven with a strong research and development component."18

The process followed by Penn State University Libraries in University Park, described by Karen Estlund in "First Steps toward a Digital Scholarship Center," comprised multiple steps. The libraries consulted with various stakeholder groups, performed a needs analysis, initiated an environmental scan, and reviewed other services on campus and off. ${ }^{19}$

Schaffner and Erway proceeded similarly, arguing that the first step in determining services and models is to find out what faculty are doing and then fill the gaps. Because every institution is different, local needs should be the focus. They determined their needs by surveying and talking with faculty, holding focus groups, reviewing online discussions, conducting a literature review, and attending DH conferences. ${ }^{20}$

Lippincott and Goldenberg-Hart note that contacting constituents and engaging them as partners rather than clients is necessary for success. ${ }^{21}$ Going where your constituents are, such as faculty departmental meetings, and engaging them there will build trust.

\section{History of Digital Initiatives at Appalachian}

Appalachian State University's digital program has grown steadily over the past 10 years. The following timeline outlines our progress. Library initiatives are denoted "(library)" and university initiatives "(university)."

$\begin{array}{ll}\text { July 2004 } & \begin{array}{l}\text { First grant-funded digital project launched (library) } \\ \text { Appalachian Collection, Stock Car Racing Collection, and } \\ \text { University Archives merged to become Special Collections } \\ \text { (library) }\end{array} \\ \text { September 2006 } & \begin{array}{l}\text { Digital Initiatives Task Force created (library) } \\ \text { CONTENTdm, storage and retrieval software for multimedia } \\ \text { June 2006 }\end{array} \\ \text { collections and other digital assets, purchased (library) } \\ \text { January 2007 } & \begin{array}{l}\text { Digital initiatives librarian position created (library) } \\ \text { Preservation and digital projects archivist position created }\end{array} \\ \text { June 2008 } & \begin{array}{l}\text { (library) } \\ \text { Omeka digital collections management platform adopted (library) }\end{array} \\ \text { January 2012 } & \begin{array}{l}\text { First Digital Humanities Symposium sponsored by Appalachian } \\ \text { April 2013 }\end{array} \\ \text { State University Humanities Council (university) } \\ \text { October 2014 } & \begin{array}{l}\text { Data Matters! Appalachian Symposium on Data Informatics } \\ \text { held, cosponsored by the library, campus IT, and the Humanities } \\ \text { Council (university) }\end{array} \\ \text { Deptember 2014 } & \begin{array}{l}\text { Digital Humanities Working Group formed (university) } \\ \text { Digital Scholarship and Initiatives Team created (library) } \\ \text { July 2015 }\end{array} \\ \text { February 2016 } & \text { Campus Technology Research Support Group formed (university) }\end{array}$

\section{Methodology}

Responding to a growing demand by Appalachian State faculty for support in their use of digital resources, the library's new dean, Joyce Ogburn, called for the creation of a 
task force to investigate the options. She appointed the Special Collections preservation and digital projects archivist as a special assistant to create and lead the task force. The group was small enough to be nimble but large enough to adequately represent the teams involved. The task force ultimately included the metadata librarian as a representative from Biblio-

The first step in determining services and models is to find out what faculty are doing and then fill the gaps. Because every institution is different, local needs should be the focus. graphic Services; the coordinator of our Technology Services team; the digital initiatives librarian, who also worked in Technology Services; the coordinator of Special Collections; and our digitization technician, also in Special Collections.

Our first move was to conduct a literature review of case studies for creating digital scholarship and digital humanities centers. We then surveyed campus faculty to determine the types of digital projects they were undertaking, what tools were being used, where they most needed support, and their base knowledge of digital scholarship and scholarly communications issues.

The survey of tenured and tenure-track faculty digital scholarship activities generated 58 complete responses (an 8 percent response rate), with around one-third coming from assistant professors. This was a low response rate, so we followed up with the campus Digital Humanities Working Group regarding the climate in individual departments. This group also included some non-humanities faculty, so we received a diversity of responses. The consensus was that, even though many faculty were doing projects that are considered digital scholarship, they did not think of their undertakings in those terms. There appeared to be little understanding regarding what constitutes digital scholarship. Another issue noted in the humanities departments was the conflict among faculty over traditional versus new forms of scholarship. Roughly 40 percent of the respondents indicated that they use some type of digital tools for scholarship or teaching, and approximately 43 percent expressed interest in receiving more information on digital scholarship and learning tools. According to the survey responses, the top five digital tools or methods faculty used in teaching were (1) video/audio production, (2)

Even though many faculty were doing projects that are considered digital scholarship, they did not think of their undertakings in those terms. There appeared to be little understanding regarding what constitutes digital scholarship. online text resources, (3) text analysis (4) data/ information visualization, and (5) online authoring tools (for example, blogs) or GIS (geographic information system) mapping. The top five digital tools or methods used in research were (1) online texts or databases, (2) digital versions of archival material, (3) online indices or concordances, (4) text analysis, and (5) online media criticism.

When asked, "Would you participate in a workshop that taught faculty how to use digital tools in the classroom?" 38 percent responded in the affirmative, and 57 percent 
indicated that they might but first wanted to know more about digital scholarship. Approximately 86 percent of the respondents said that they were interested in publishing support for journal articles. The survey established, in other words, that a core group of faculty considered themselves digital scholars, and a larger group had sufficient interest to request more information and education on the topic.

We next looked at what types of services were offered elsewhere on campus. These were scattered, without any formal cooperation between departments to meet scholarship needs. The university's Office of Research provided support to faculty seeking grants, including help with data-management

A core group of faculty considered themselves digital scholars, and a larger group had sufficient interest to request more information and education on the topic. plans. The Office of Research offered guidance for the collection, editing, verification, and management of quantitative, statistical, and biostatistical data. It also supplied assistance and resources to help faculty with the collection, management, and analysis of data from ongoing research projects using a variety of software. Our campus IT (Information Technology Services) provided support for many types of software, as well as for equipment, Web design, database development and hosting, virtual environments, data storage and backup, and high performance computing. Digital scholarship was supported by University Documentary Film Services and through training provided by the Humanities Council and Digital Humanities Working Group, which sponsored speakers and workshops for campus. Finally, the College of Arts and Sciences maintained a visualization lab to support its departmental programs.

We also surveyed the library's offerings. Our Technology Services team provided an audio recording room, a digital media studio, software instruction, and equipment checkout. They also offered Web design, software, and equipment support. Our Bibliographic Services team provided metadata services, and Special Collections did most of the digitization of the collection. We also had a new scholarly communications and intellectual property librarian who reported directly to the dean of libraries.

Finally, we investigated programs at other campuses. Members of the task force visited the University of Maryland, College Park; George Mason University in Fairfax, Virginia; the University of North Carolina at Charlotte; and the University of Tennessee, Knoxville. We also spoke by telephone with Virginia Polytechnic and State University (Virginia Tech) in Blacksburg. All these programs were well developed, and each was affiliated with the university's library. Since we had no funding for our study, it was important that the schools be geographically close, so we could drive to them. We wanted to visit a range of schools representing our aspirational peers, research-intensive (R1) universities and liberal arts schools. Importantly, the group also included a school that, like Appalachian, was within the University of North Carolina system. We chose two of the schools from the CNI Workshop report "Digital Scholarship Centers: Trends \& Good Practice." We asked each center: 
1. What is your mission statement?

2. What services do you offer?

3. What space do you have?

4. What is your reporting structure?

5. What positions do you have to support your work?

6. How are you funded? Do you have your own budget line?

\section{Recommendations and Implementation}

Of the three main program models — virtual, physical center, or hybrid-we determined that the best option for our institution was the hybrid model described in Zorich's report A Survey of Digital Humanities Centers in the United States. This approach involved creating a new team with a core group of staff dedicated to digital projects. We would work with our partners, whom we identified through the campus and library surveys, to fill the gaps. Working from our research findings, we determined that our initial services should include (1) digital imaging and reformatting; (2) preservation, data curation, and Web harvesting for the university; (3) text analysis; (4) consultations on project management, preservation, curation, and project development; (5) workshops and training; (6) grant-writing assistance related to digital projects; (7) hosting speakers and workshops; (8) scholarly communications and intellectual property rights consultation and education; (9) electronic records management; (10) and publishing. The library already offered these services on some level except for text analysis and publishing support. Our digitization, curation, and preservation services now extended to faculty, and we offered more training and education on the Omeka Web publishing platform, metadata standards, and copyright issues.

The electronic records component was an agreement between the new team and the university archivist, with whom we now worked closely, along with other units on campus to create a university electronic records program. We expected that publishing services would become important in our future, so we wanted to start planning at the beginning.

\section{Staffing}

Our next challenge was to determine who would be on the core team. We had in-house expertise to fill some of the staffing needs but knew we would eventually need additional positions for other services. The former preservation and digital projects archivist from the Special Collections team took the role of coordinator, managing the team staff and activities and providing project management, consulting, and training. Our digital projects librarian came from Bibliographic Services. Our scholarly communications and intellectual property librarian worked in Technology Services. The digital imaging specialist, who would also provide Omeka and digital-image training, was from Special Collections. Our electronic records and digital assets manager, who would manage the curation and preservation of our digital materials and electronic records as well as our audiovisual digitization program, also came from Special Collections. In addition, we utilized student assistants (70 hours per week) for digitization production work. 
To sustain Omeka and do other projects, we determined that we would need an additional programmer. With only one programmer on the library staff, we needed another to support faculty projects. Also, given the interest in publishing services, we anticipated that we would eventually need someone to manage digital publishing.

\section{Space and Equipment}

The libraries had hired a consultant to develop a new space plan for the entire library. Digital Scholarship and Initiatives secured space on the third floor adjacent to the Technology Services Team, large enough for offices and two workrooms, one for audiovisual $(\mathrm{AV})$ and one for imaging.

Since we already had an active digitization program, we had all the necessary equipment, which was transferred to the new area. The move left the Special Collections area with space for new staff and workrooms.

\section{The First Year}

Our first action as a team was to create our mission statement:

Digital Scholarship and Initiatives (DSI) engages and partners with Appalachian faculty members, students, library colleagues, and the community to support new scholarship in a rapidly changing digital landscape. DSI provides and sustains innovative digital tools and publishing platforms for content delivery, discovery, analysis, data curation, and preservation. In line with the Library's mission, we enhance student learning and encourage faculty research, primarily by providing access to and information about new methods of digital scholarship. We also lend support to campus faculty and students in the areas of copyright and intellectual property.

Next, we created goals for the year, which required that we write new job descriptions for the team staff. The team had four goals for the first year:

1. Build education and consulting services that promote, support, and facilitate the production of digital scholarship.

2. Create partnerships with campus and community constituents to develop digital content.

3. Develop and implement solutions for the ongoing preservation of born-digital and digitized materials.

4. Promote the institutional repository (IR) to Appalachian State University faculty to increase the quantity and range of items archived in the university IR.

The team decided to focus on developing the services we already offered and on building our infrastructure. Our four service areas were (1) digital scholarship, (2) digital preservation, (3) digital access, and (4) scholarly communications. Digital scholarship includes consultation and project management services, project collaboration, and workshops and events. Our digital preservation services are electronic records and digital asset management, data curation, and storage. We provide digital access through digitization services and by maintaining data repositories, digital content management systems, and the institutional repository. Our scholarly communications and intellectual property librarian provides education and consultation services regarding copyright, intellectual property, and open access publishing. 
We developed our website to promote these services and created policies, procedures, and workflows to assist with faculty projects and to work with our partners in creating and maintaining those projects. We had assumed that the first year would be spent pulling together our infrastructure, but word got out about the new team, and we found ourselves working on 18 projects, including multiple grant projects. This high level of demand was a surprise, because the only marketing we did was through the website and talks with various groups, including the library faculty, our Digital Humanities Working Group, the University Research Council Technology Support Committee, the Provost's Council, and our Library Advisory Board. We did not send out announcements about the services, thinking it best to first make certain we had our infrastructure ready.

The projects in the first year included creating data management plans, open source publishing, and digital collections; sponsoring workshops on digital tools and copyright; cosponsoring Home Movie Day, THATCamp (the Humanities and Technology Camp), and the Digital Appalachia Lecture Series; partnering with the local historical society and the public library to create a Web portal for Appalachia-related digital collections; participating in three grant projects with local history organizations; working with a graduate class to help the students create Omeka exhibits; and implementing a Humanities Open Book grant from the National Endowment for the Humanities and the Andrew W. Mellon Foundation to digitize publications of the former Appalachian Consortium Press, which dissolved in 2004.

During this first year, we solidified partnerships with library departments and developed new campus and community collaborations. The two most important partnerships developed were with the University of North Carolina (UNC) Press and Appalachian State's newly formed Technology Research Support Group.

We now work with UNC Press to provide publishing services for Appalachian State that include EPUBS, a format for digital books established by the International Digital Publishing Forum, and print-on-demand. The imprint or publisher for these items is Appalachian State, with UNC Press providing the digitization and dissemination services. We partnered with Information Technology Services and the Office of Research to create a Technology Research Support Group, which provides research help to campus faculty. Each of our units offers different services. If a faculty member approaches one of us with a need that we cannot fulfill, we send that request to our Google+ group, with whom we consult on how to solve the issue. It is a simple solution but has proved effective.

\section{One challenge we faced was a lack of understanding about digital scholarship and schol- arly communications among some faculty.}

\section{The Challenges and How We Could Have Done It Better}

One challenge we faced was a lack of understanding about digital scholarship and scholarly communications among some faculty, as demonstrated by the survey. Even some of the faculty who actively produced digital scholarship did not think of their work in those terms. The survey responses of a few campus faculty indicated outright hostility toward the idea of digital scholarship and a clear lack of understanding of the 
technology. On most campuses, including ours, there is still some resistance to new forms of scholarship.

There was also some reluctance among library faculty to commit resources to a larger digital program, primarily because of competition for resources. A few also believed the faculty's need for these services was insufficient to warrant adding resources. The fear that digital and technology services would come at a cost to more traditional services and collections prevented some individuals from seeing the possibilities of a digital scholarship program. There was concern that committing to a program was a risky venture without assurances that our potential clientele would be responsive to our service offerings or willing to engage in partnerships with the library.

Additionally, because we were in the middle of a reorganization and working with a consultant on a new space plan, we were on a tight timeline for deciding about digital services. If we were to create a new unit in the library, we would need space, and the teams that would lose staff to the new team would need to adjust the plan for their spaces. This adjustment left us with less time for educating our constituents and potential partners as well as less time to gather information.

These challenges could have been addressed simply by building in more time and moving into the project gradually. Education and communication are key components in making any new initiative successful; both, however, take time and require a consistent message, effective listening, and engagement with stakeholders. If we had the time

For library colleagues or administrators who are skeptical about a digital scholarship program because of a lack of understanding of new technologies and their uses in teaching and scholarship, education can help. to hold more focus groups and workshops, visit more academic departments, and distribute information about digital scholarship and scholarly communications, our survey response might have been stronger and the concepts less intimidating to those unfamiliar with them.

For library colleagues or administrators who are skeptical

about a digital scholarship program because of a lack of understanding of new technologies and their uses in teaching and scholarship, education can help. Providing examples or holding short sessions to highlight a new tool can eliminate much of the anxiety about new technology, particularly if you focus on tools that relate directly to an individuals' research or teaching.

Hiring an outside consultant would also have strengthened our case for the digital scholarship program. Having a neutral outside party provide recommendations may be more acceptable to some, particularly in libraries embroiled in political and resource conflicts. Also, an outside observer may identify issues and opportunities that those close to the institution overlook.

Our advice to libraries is to focus on four points as they create digital scholarship services:

1. Time. Take adequate time-defined, perhaps, as the more conservative of your early estimates-to do all the research and to be thorough in your program proposal. 
2. Education. Start educating your stakeholders even before you start gathering information from them. Their responses to your surveys, discussions, and other information-gathering efforts will be more informed and more useful.

3. Research. Be thorough in gathering your information, which will allow you to be detailed in its presentation. Use multiple methods for gathering input. There may be unanticipated objections to your recommendations, but most can probably be addressed with documentation.

4. Communication. Support for and understanding of your efforts, whether on the part of the wider faculty or within the library itself, depends on effective communication. Let individuals know what they stand to gain; make them stakeholders in your success.

\section{Summary}

Effective planning will help ensure that the program is supported and sustainable. Creating a digital scholarship program need not be an all-or-nothing situation. As Schaffner and Erway recommend, you can start small. "Packaging" virtual services requires little investment, and you can always scale up as needs change. ${ }^{25}$

As NYU Libraries had before us, we considered the different models and determined that a small core staff of subject specialists would best suit our needs. Working with library and campus partners helped us determine the services on which to focus.

From our research and experience, we have developed an outline for laying the groundwork for a digital scholarship program:

1. Start with your institution's mission and strategic plan goals. You must be ready to explain how the program supports the institution's mission and goals. This is crucial for funding support.

2. Create a timeline for information gathering. Plan for enough time to gather all the information and present your program proposal.

3. Identify your partners, who will be your key stakeholders. They include users, other units in the library and on campus who provide digital scholarship services, library and campus administration, your library advisory board, and potentially others.

4. Survey your current services and perform a gap analysis. The library probably already offers certain services; consider how they can be repackaged to present a cohesive program. Explore what services should be eliminated or enhanced, and then determine what services should be added.

5. Gather information on resources. Start with what you have already in terms of staffing, space, equipment, and funding.

The library probably already offers certain services; consider how they can be repackaged to present a cohesive program. Determine how those resources can be pooled together and how the initiative will be funded in the future, after growth. Also consider reporting structure: for example, does your unit report directly to either the associate dean, dean, or provost? The reporting structure can influence funding support as well. 
6. Look at what other services are offered on campus. Other campus departments may provide related research assistance. These are potential partners in your program.

7. Ask how you can work with these units to provide a suite of services.

8. Include education for constituents. Focus groups are a good start, but informal discussion sessions, mini workshops, conversations with individuals, and the sharing of information via your website, e-mail, and other venues all create awareness of the issue.

9. Do not forget to include sustainability in your plans. Starting small and building gradually can help ensure success of your program. Sustaining both resources and partnerships requires planning.

Pamela Price Mitchem is an associate professor and the coordinator of digital scholarship and initiatives at the Belk Library and Information Commons of Appalachian State University in Boone, North Carolina; she may be reached by e-mail at: pricemtchemp@appstate.edu.

Dea Miller Rice is an assistant professor and digital projects librarian at the Belk Library and Information Commons of Appalachian State University in Boone, North Carolina; she may be reached by e-mail at: ricedm@appstate.edu.

\section{Notes}

1. Appalachian State University Libraries, "Library Plan 2016 and Beyond," accessed March 15, 2017, http:/ / library.appstate.edu/sites/ library.appstate.edu/files / documents/library_ strategic_plan_2016.pdf.

2. Diane Goldenberg-Hart, "Report of a CNI [Coalition for Networked Information]-ARL [Association of Research Libraries] Workshop: Planning a Digital Scholarship Center," accessed August 19, 2016, https: / / www.cni.org/wp-content/uploads /2016/08 / reportDSCW16.pdf.

3. Jennifer Schaffner and Ricky Erway, "Does Every Research Library Need a Digital Humanities Center?" Online Computer Library Center (OCLC), 2014, 7, accessed August 19, 2016, http:/ / www.oclc.org/content/dam/research/ publications / library / 2014 / oclcresearch-digital-humanities-center-2014.pdf.

4. Chris Alen Sula, "Digital Humanities and Libraries: A Conceptual Model," Journal of Library Administration 53, 1 (2013): 16.

5. Diane Zorich, A Survey of Digital Humanities Centers in the United States (Washington, DC: Council on Library and Information Resources, 2008), 4, vi, accessed August 21, 2016, https: / / www.clir.org/pubs/ reports / pub143/pub143.pdf.

6. Edward L. Ayers, "Does Digital Scholarship Have a Future?" EDUCAUSE Review 48, 4 (2013): 27, accessed July 22, 2016, http: / / er.educause.edu / articles / 2013/8/does-digitalscholarship-have-a-future.

7. Charles Inskip, "From Information Literacy to Digital Scholarship: Challenges and Opportunities for Librarians," slide presentation, University College London, 2015, accessed July 27, 2016, http:/ / www.cilip.org.uk/sites/default/ files/Inskip_ARLG-web. pdf.

8. Joan K. Lippincott and Diane Goldenberg-Hart, “Digital Scholarship Centers: Trends \& Good Practice," CNI, 2014, 1-2, accessed July 23, 2016, https: / www.cni.org/wp-content/ uploads / 2014/11/CNI-Digitial-Schol.-Centers-report-2014.web_.pdf.

9. Zorich, A Survey of Digital Humanities Centers in the United States, 71.

10. Schaffner and Erway, "Does Every Research Library Need a Digital Humanities Center?" 5. 
11. Tim Bryson, Mariam Posner, Alain St. Pierre, and Stewart Varner, SPEC [Systems and Procedures Exchange Center] Kit 326: Digital Humanities (Washington, DC: ARL, 2011).

12. Joyce L. Ogburn, "A Report on the Digital Humanities and Concept Paper for a Virtual Center for Interdisciplinary Knowledge Arts," unpublished paper, University of Utah, Salt Lake City, 2013, 7.

13. Sula, "Digital Humanities and Libraries," 22.

14. Joris van Zundert, "If You Build It, Will We Come? Large Scale Digital Infrastructures as a Dead End for Digital Humanities," Historical Social Research/Historische Sozialforschung 37, 3 (2012): 165, 183.

15. Jennifer Vinopal and Monica McCormick, "Supporting Digital Scholarship in Research Libraries: Scalability and Sustainability," Journal of Library Administration 53, 1 (2013): 27-42.

16. Ibid.

17. Ibid.

18. Ibid.

19. Karen Estlund, "First Steps toward a Digital Scholarship Center," slide presentation, University of Oregon Libraries, 2013, accessed July 23, 2016, http: / / www.slideshare.net/ kestlund/estlund-educause-dighum.

20. Schaffner and Erway, “Does Every Research Library Need a Digital Humanities Center?"14.

21. Lippincott and Goldenberg-Hart, "Digital Scholarship Centers: Trends \& Good Practice."

22. Schaffner and Erway, "Does Every Research Library Need a Digital Humanities Center?"14. 